\title{
Sexual interference of the floral kind
}

\author{
SCH Barrett \\ Department of Botany, University of Toronto, 25 Willcocks Street, Toronto, Ontario, Canada M5S 3B2
}

Floral hermaphroditism results in conflicts and compromise
in the parental roles of plants during pollination and mating.
A potential cost of hermaphroditism is sexual interference
between maternal and paternal functions resulting in gamete
wastage and reduced fitness. Sexual interference may or
may not be associated with self-pollination. In cases where
self-pollination occurs, ovule or pollen discounting may
reduce mating opportunities. Here I describe forms of sexual
interference in flowering plants, distinguishing whether

physical or biochemical interactions are involved and whether fitness costs associated with gamete wastage arise from intra-floral versus inter-floral processes. I review the limited experimental evidence for interference between sex functions and evaluate the hypothesis that some floral adaptations usually interpreted as anti-selfing mechanisms may serve an alternative function in reducing mating costs arising from this form of sexual conflict.

Heredity (2002) 88, 154-159. DOI: 10.1038/sj/hdy/6800020

Keywords: plant sexuality; hermaphroditism; sexual interference; ovule and pollen discounting; dichogamy; enantiostyly

\section{Introduction}

The fundamental sexual condition of the vast majority of flowering plant species is hermaphroditism (cosexuality). Hermaphroditic individuals both receive and disperse pollen and may ultimately function as both maternal and paternal parents to the next generation of individuals. These dual sex roles can result in conflicts and compromise in the parental roles of plants during pollination and mating (Lloyd and Yates, 1982; Bertin and Newman, 1993; Fetscher, 2001). Although hermaphroditism can provide an economy of resources because allocation to floral attraction and reward benefits both maternal and paternal function (Charnov et al, 1976), this advantage does not come without the potential of exerting considerable reproductive costs. The principal cost of hermaphroditism is self-fertilization and the reduced fitness of offspring resulting from inbreeding depression (Charlesworth and Charlesworth, 1987). Since Darwin (1876), the adaptive significance of floral diversity has largely been interpreted as resulting from the promotion of cross-pollination and selection to avoid self-fertilization and the harmful effects of inbreeding.

Floral hermaphroditism can also result in reproductive losses unrelated to the specific genetic costs of inbreeding depression. These losses may or may not involve selfpollination and arise from functional conflicts between traits promoting pollen deposition on stigmas and pollen removal from anthers. While many features of floral design and display serve both functions equally, what is optimal for one process may not necessarily be optimal for the alternate sex role. As a result, there is potential for sexual interference between maternal and paternal

Correspondence: SCH Barrett, Department of Botany, University of Toronto, 25 Willcocks Street, Toronto, Ontario, Canada M5S 3B2. E-mail: Barrett@botany.utoronto.ca functions resulting in gamete wastage and reduced reproductive potential. The realization that many plants are protected from the harmful effects of self-fertilization by physiological self-incompatibility, yet still possess floral traits traditionally interpreted as 'anti-selfing mechanisms' has stimulated efforts to find other explanations for their origin and maintenance (eg, Lloyd and Webb, 1986; Webb and Lloyd, 1986; Bertin, 1993; Harder and Barrett, 1995). Sexual interference represents a plausible alternative explanation although at present its ecological and evolutionary significance is not well understood.

Here the concept of sexual interference in flowering plants is reviewed focusing on animal-pollinated species where the phenomenon has most often been discussed. The different ways that sexual interference can potentially be manifested are outlined paying attention to physical versus chemical interactions between sex functions and whether fitness costs associated with gamete wastage arise from intra-floral versus inter-floral processes. Empirical evidence for interference between sex functions, focusing in particular on the role of ovule and pollen discounting in reducing mating opportunities, is reviewed. Finally, the hypothesis that some floral adaptations, usually interpreted as anti-selfing mechanisms, may serve an alternative function in reducing male mating costs arising from this form of sexual conflict is evaluated.

\section{Forms of interference}

Sexual interference will be most important in simultaneous hermaphrodites in which both pollen and stigmas are presented at the same time within flowers. Species most susceptible to interference are those in which pistils and stamens are located in close proximity. Interference will obviously be absent from dioecious species but will also be reduced in intensity in species with unisexual flowers (eg, monoecy), or in those with 
well-developed spatial and temporal segregation of female and male function within flowers (eg, herkogamy and dichogamy, respectively). Short-lived flowers are more likely to experience sexual interference than longlived flowers. This is because of the restricted window of time available for developmental changes to sex-organ position that might alleviate conflicts between female and male function. Sexual interference can also occur between flowers within a plant and is likely to be most severe in species with large floral displays.

Sexual interference can potentially take several distinct forms with contrasting reproductive consequences. Interference between female and male function has most often been recognized as occurring within flowers and has been referred to as pollen-stigma or pollen-pistil interference (see Bertin and Newman, 1993). Two different types of intra-floral interference are commonly recognized. In the first, the structure or position of female and male sexual organs within a flower may physically interfere with efficient pollination. This occurs either when stamens impede proper pollinator positioning resulting in poor pollen deposition on stigmas leaving ovules unfertilized, or when features of pistils prevent effective pollen pickup by pollinators hence reducing pollen export. The second form of interference involves the 'pollen clogging' effect whereby female function is compromised because of the negative effects of self-pollination. While this phenomenon is often discussed with respect to intra-floral self-pollination the source of self pollen is largely irrelevant and both within and between flower pollination may be involved. Indeed, as discussed below there are reasons to believe that in many cases reproductive interactions among flowers on a plant may be the most functionally significant source of sexual interference.

Before the evidence for these forms of interference is reviewed it is worth pointing out that empirical evidence for them is quite scant and it remains to be seen whether they represent important reproductive factors governing floral evolution. Two problems arise in evaluating the ecological and evolutionary significance of sexual interference. First, if sexual interference has been an important selective force shaping floral traits, demonstrating its occurrence may be difficult because extant traits should have evolved to minimize its intensity in contemporary populations. Only through the use of experimental manipulations might it be possible to create the ancestral phenotypes that are postulated to have been susceptible to sexual interference. Second, it is often difficult to distinguish between the anti-selfing and sexual interference hypotheses to account for floral adaptations. This is because self-pollination is a requirement of the antiselfing hypothesis but is also involved in some forms of interference. Thus as pointed out by Bertin and Newman (1993) adaptations for limiting self-pollination may have been selected because of advantages related to the avoidance of inbreeding and/or because they reduce sexual interference. With these caveats in mind I next review experimental evidence for sexual interference in plants.

\section{Physical interference between sex functions}

Herkogamy is the spatial separation of anthers and stigmas within flowers. In 'movement herkogamy' the separation arises through developmental changes to sexorgan position during the lifetime of a flower. Touch- sensitive stigmas in which stigma lobes close rapidly in response to contact by pollinators occur commonly in the order Scrophulariales and represent an example of movement herkogamy. Webb and Lloyd (1986) proposed that stigma closure may function to reduce sexual interference rather than the traditional view that it represents a mechanism to reduce intra-floral self-pollination. A recent study by Fetscher (2001) of hummingbird pollinated Mimulus aurantiacus (Scrophulariaceae) provides experimental evidence to support their interpretation. Manipulations of stigma closure demonstrated that flowers with closed stigmas dispersed twice as much pollen to other flowers as those that were open (Figure 1). Moreover, whether stigmas were open or closed had little influence on levels of self-pollination. This study is significant because it demonstrates for the first time that a floral trait can serve to reduce female interference with male function independently of any influence on self-pollination. The only other experimental study to examine female interference with male function failed to demonstrate any significant influence on male siring success of the presence versus absence of pistils within a flower (Kohn and Barrett, 1992).

The opposite form of physical interference involves stamens obstructing the deposition of outcrossed pollen on stigmas. Two widespread features of flowers involving the segregation of female and male function are likely to reduce the occurrence of this form of sexual interference and may have been selected, in part, because they serve this role. The most prevalent form of dichogamy is protandry, in which pollen is dispersed from anthers before stigmas are receptive (Lloyd and Webb, 1986). Generally stamens wither or move away from pistils during female function thus reducing opportunities for interference to occur. Similarly, approach herkogamy, where stigmas are exserted and are positioned above anthers in flowers, is much more prevalent than the reverse sequence (reverse herkogamy - Webb and Lloyd, 1986). Interference is min-

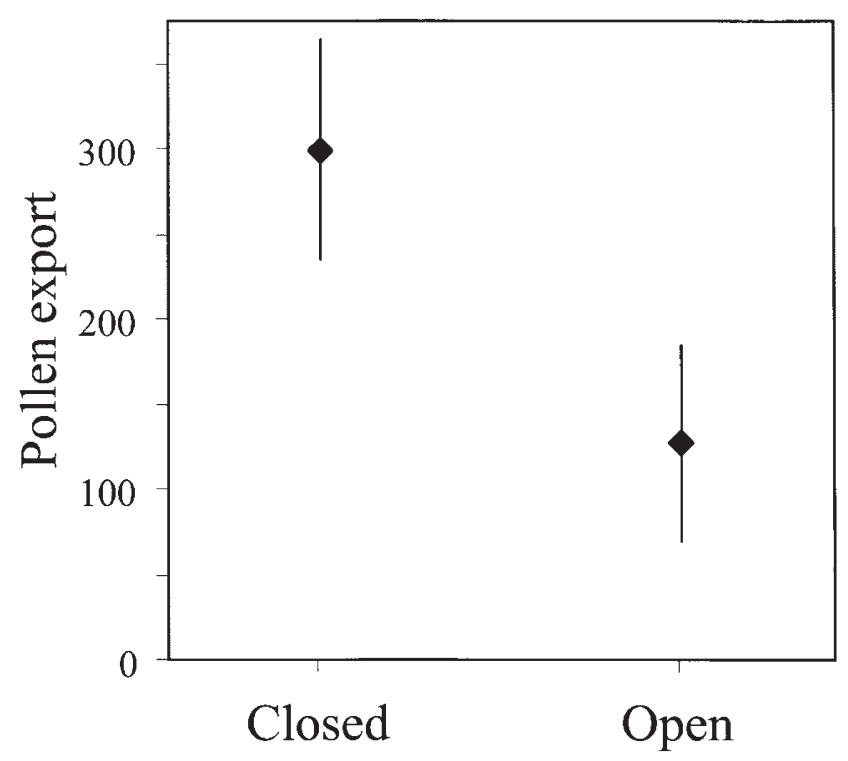

Figure 1 Intra-floral interference of male function by female function. The influence of stigma closure on pollen export to other plants in experimental arrays of Mimulus aurantiacus. Redrawn from Fetscher (2001). 
imized in approach herkogamy because stigmas usually contact pollinators first on entry into a flower. To our knowledge there is no experimental evidence demonstrating that stamens reduce cross pollen capture by stigmas. Barrett and Glover (1985) compared compatible pollen loads on stigmas of emasculated versus intact flowers of tristylous Pontederia cordata (Pontederiaceae) to assess the interference hypothesis. They were able to distinguish compatible from incompatible pollen on stigmas because of distinct pollen-size trimorphism in this species. There were no significant differences among the style morphs in the number of compatible pollen grains deposited on stigmas by bumblebees visiting flowers with and without stamens. More manipulative studies comparing intact flowers with those in which the sex organs have either been altered in position or removed would be valuable to assess the physical interference hypothesis.

\section{Pollen clogging and ovule discounting}

The presence of self pollen on stigmas of self-incompatible plants can have two potentially important reproductive consequences. First, self pollen may interfere with female function resulting in reduced fertility because of lower fruit and seed set. Second, self pollen on stigmas is not available for pollen export to other plants and may therefore reduce male siring success (pollen discounting - Harder and Wilson, 1998). This section focuses on the first of these two processes since there is growing evidence that self-pollination in selfincompatible plants may incur significant reproductive costs. Pollen discounting will be discussed in the following section.

Virtually all investigations of the costs of selfpollination in self-incompatible plants have employed either pollen chase experiments in which stigmas are pollinated first with self pollen and then with cross pollen, or have used mixtures of self and cross pollen. In most studies significant reductions in fertility were evident, with the specific level depending on treatment. For example, Broyles and Wyatt (1993) found that in Asclepias exaltata (Asclepiadaceae) self pollen reduced the ability of cross pollen to fertilize ovules and mature fruits by $49 \%$ in mixed pollinations and by $81 \%$ when self pollen was applied prior to cross pollen. Similar results have also been obtained by Bertin and Sullivan (1988), Galen et al (1989), and Waser and Price (1991). However, not all studies have demonstrated negative effects of prior selfpollination on fertility. In distylous Turnera ulmifolia (Turneraceae) and tristylous Pontederia cordata, Shore and Barrett (1984) and Barrett and Glover (1985), respectively, found little influence of prior self-pollination on seed set. In tristylous Pontederia sagittata the inhibitory effects of prior self-pollination varied positively with style length, with long-styled flowers showing the greatest susceptibility to pollen-pistil interference and short-styled flowers exhibiting no harmful effects (Scribailo and Barrett, 1994). Yeo (1975) proposed that many of the floral polymorphisms that characterize heterostylous species could function as 'anti-clogging' mechanisms reducing the harmful effects of incompatible pollen. Stigma polymorphisms in particular may serve to reduce the likelihood of interference between compatible and incompatible pollen as a result of the topographical complementarity between pollen grains and stigma surfaces (Dulberger, 1992).

Negative influences of self-pollination on female function have been thought to arise because self pollen restricts access of cross pollen to stigma surfaces or self pollen tubes interfere with cross pollen-tube growth in the style or ovary. These interactions could be physical in nature and associated with competition for space. Indeed the term 'pollen clogging' has often been used to refer to these physical interactions although it seems highly likely that biochemical interactions are also involved. Unfortunately, while there is good experimental evidence for the inhibitory effects of self pollen on female fertility the precise mechanisms of pollen-pistil interaction that limit fertility have rarely been investigated. Moreover, studies evaluating the ecological and evolutionary significance of this form of sexual interference have rarely included the range of compatible and incompatible pollen loads that populations commonly experience in the field as well as their temporal dynamics.

Several studies demonstrating reduced female fertility following mixed or prior self-pollination involve species with late-acting self-incompatibility systems with selfrejection in the ovary (eg, Waser and Price, 1991; Lloyd and Wells, 1992; Broyles and Wyatt, 1993; Seavey and Carter, 1993). The ovule wastage that accompanies selfpollination in species with late-acting incompatibility has been difficult to interpret in functional terms and has often been viewed as maladaptive. Recent studies of Narcissus (Amaryllidaceae) species provide clues as to the functional basis of the mechanisms involved and also suggest that interference between female and male functions may have played a role in the evolution of sexual systems in the genus (Barrett et al, 1996, 1997; Sage et al, 1999; Baker et al, 2000a, b; J Arroyo and SCH Barrett, unpublished data).

Stylar polymorphisms occur in approximately 12 species of Narcissus in four sections of the genus. Phylogenetic evidence based on molecular data from several chloroplast genes indicates multiple origins of stylar polymorphism (SW Graham and SCH Barrett, unpublished data). In species with stigma-height dimorphism the initial invasion of the short-styled morph into ancestral longstyled populations appears to have been associated, in part, with pollen-pistil interference and the costs associated with self-pollination (Barrett et al, 1996). All species with stylar polymorphism in the genus have constricted floral tubes and are pollinated by long-tongued lepidoptera and bees. 'Packing constraints' governing the proximity of stigmas and anthers at the mouth of the floral tube and their influence on self-pollination may have favoured the spread of variants with short-styles. In sexually dimorphic Narcissus species the distance separating sex organs is on average four times greater in the short-styled morph compared to the long-styled morph (Barrett et al, 1996; Baker et al, 2000a). Hence this 'anti-clogging' morphology probably reduces costs associated with either autonomous or pollinator mediated influences. Theoretical models incorporating the relative costs associated with self-pollination and the effectiveness of the morphs as pollen parents can explain the maintenance of these sexual polymorphisms (Barrett et al, 1996; Baker et al, 2000b)

Experimental evidence indicates that prior self- 
pollination of cross-pollinated flowers of Narcissus species results in a significant reduction in seed set in comparison with cross-pollinated controls (Figure 2). The mechanism responsible for this response has recently been investigated in $N$. triandrus and involves a novel form of pollen-pistil interaction involving differential ovule development in response to cross- versus self-pollination (Sage et al, 1999). Comparisons of self and cross pollen-tube growth indicate that both reach ovaries at the same time, yet only cross-pollinations yield significant levels of seed set. Self-incompatibility results from embryo sac degeneration following self-but not cross-pollination causing a reduction in the availability of fertile ovules. The different developmental responses of ovules are evident well before pollen tubes enter ovaries implicating 'long-distance' signalling events between pollen tubes and ovules. The implications of these results are that self-pollination of Narcissus flowers, while not resulting in genetic costs associated with selfing, could still exert reproductive costs in the form of ovule discounting - the exclusion of ovules from cross-fertilization because they are rendered non-functional as a consequence of self-pollination (Barrett et al, 1996). Other species with late-acting (ovarian) self-incompatibility need to be investigated to determine whether similar mechanisms involving differential ovule development following cross-versus self-pollination occur.

How costly is the ovule wastage that is associated with late-acting self-incompatibility and is it maladaptive? The pollen-pistil signalling mechanism in $N$. triandrus, while probably resulting in some short-term costs associated with ovule discounting, may actually save resources in the long term. By minimizing investment in selfed seeds, plants can store resources for future flowering episodes when the pollination environment may be more conducive for cross-pollination. There are several reasons why this may be particularly important in $N$. triandrus. First, $F$ values in populations of this species are close to zero indicating that there is strong selection against the small amount of selfed seed that is produced in populations because of leaky self-incompatibility. Second, $N$. triandrus, like most Narcissus species, is an early-spring bulbous geophyte that flowers at a time when pollinator service is notoriously unreliable. In years in which selfpollination is frequent it may pay plants to not invest in seeds that make little contribution to fitness, but rather
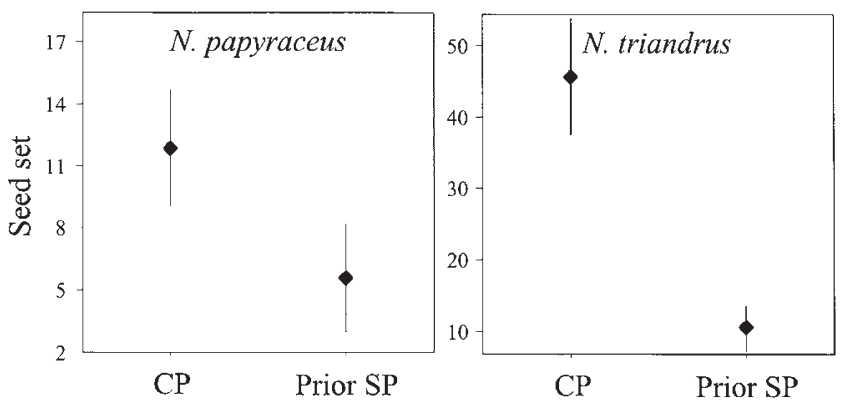

Figure 2 The inhibitory effects of prior self-pollination on outcrossed seed set in two self-incompatible Narcissus species: N. papyraceus - J Arroyo and SCH Barrett, unpublished data; N. triandrus - Barrett et al (1996). CP = cross-pollinated flowers, Prior $\mathrm{SP}=$ flowers that were self-pollinated first and then cross-pollinated after 24 ( N. triandrus) or 48-72 (N. papyraceus) hours. save resources for future reproduction, hence increasing lifetime fitness. This could be important in N. triandrus since plants are long-lived but usually produce only one to three flowers per season and therefore each flower represents a large fraction of a plant's annual total reproductive effort. While further work on N. triandrus is needed to establish the threshold levels of self-pollination that elicits ovule sterilization, these results do reveal potentially unexpected functional connections between sexual interference and life history.

\section{Geitonogamous pollen discounting}

In most angiosperm species, more than one flower on a plant is sexually active on a given day and therefore interactions between flowers on a plant can influence pollination and mating. In many plants with large floral displays, the major source of self-pollination is inter-flower (geitonogamous) pollination. Geitonogamous selfpollination can be viewed as a form of inter-floral sexual interference since it has the potential to waste male gametes that could be exported to other plants. Harder and Barrett (1995) demonstrated that geitonogamous pollen discounting increased with flower number per plant in experimental arrays of Eichhornia paniculata (Pontederiaceae). They suggested that this largely unappreciated male mating cost of large floral displays could be an important selective force influencing floral traits. They proposed that floral adaptations commonly interpreted as anti-selfing mechanisms, such as dichogamy, andromonoecy, and heterostyly, may function to relieve sexual interference by reducing geitonogamous pollen discounting (Harder and Barrett, 1996). A recent experimental test of their hypothesis provides support for the view that the segregation of female and male function among flowers on an inflorescence through dichogamy, or the production of unisexual flowers, relieves the constraint that geitonogamous pollen discounting imposes on a plant's ability to attract pollinators through large floral displays (Figure 3 and see Harder et al, 2000).

Enantiostyly, the production of mirror-image flowers differing in style orientation, may also serve as a means of reducing geitonogamous self-pollination in a manner functionally analogous to heterostyly. This sexual poly-
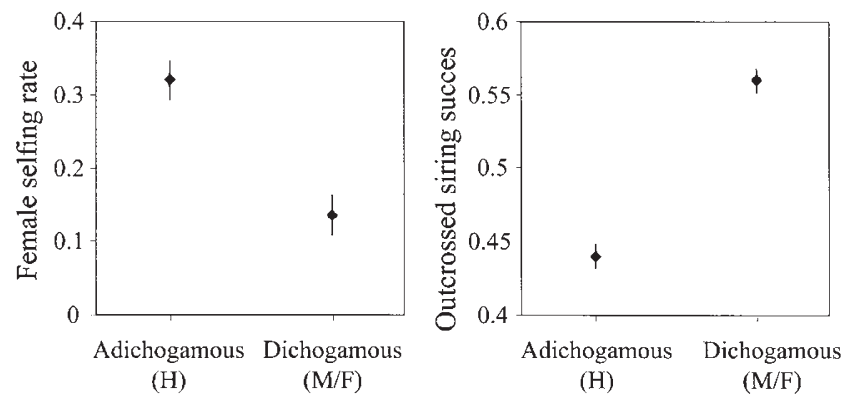

Figure 3 Inter-floral interference of female function by male function. Female selfing rates and outcrossed siring success of adichogamous and dichogamous plants in experimental arrays of Eichhornia paniculata. Adichogamous plants had five flowers that presented both stigmas and pollen simultaneously, simulated dichogamous plants had 10 flowers with the bottom five female and the top five male. Both phenotypes produced equivalent numbers of female and male gametes and were competed in 50:50 arrays. See Harder et al (2000) for experimental details. 
morphism occurs in at least 10 angiosperm families and has been known for over a century (Todd, 1882) although it was not treated by Darwin (1877) in his seminal book on plant sexual polymorphisms. Two distinct forms of enantiostyly occur, both involve the deflection of the style to the left- or right-side of the flower (Barrett et al, 2000a, b). In monomorphic enantiostyly both left and rightstyled flowers occur on the same plant, whereas in dimorphic enantiostyly plants in populations are either left- or right-styled. Recent work on mirror-image flowers has provided answers to questions concerning the evolution and maintenance of these curious forms of directional asymmetry (LK Jesson and SCH Barrett, unpublished data).

In Wachendorfia (Haemodoraceae) all four species in the genus exhibit dimorphic enantiostyly but the expression of the polymorphism differs among species because of their contrasting reproductive systems (Jesson and Barrett, in press). Population style-morph ratios range from 1:1 in outcrossing $W$. paniculata to stylar monomorphism in predominantly selfing $W$. parviflora and clonal $W$. thyrsiflora. In W. brachyandra, a species with delayed selfing, morph ratios are usually biased. The occurrence of equal morph ratios in $W$. paniculata is probably indicative of a balanced genetic polymorphism maintained by negative frequency-dependent selection mediated by disassortative mating. It seems likely that, in common with heterostyly, this mating pattern in enantiostylous species is facilitated by insect pollinators that cause greater levels of inter-morph compared to intra-morph cross-pollination as a result of segregated pollen deposition on different sides of the pollinators' bodies. Although the inheritance of dimorphic enantiostyly is not known in Wachendorfia, genetic studies in Heteranthera multiflora (Pontederiaceae) indicate that the control of style orientation is governed by a single diallelic locus with rightbending styles dominant to left (LK Jesson and SCH Barrett, unpublished data). With this inheritance and similar levels of disassortative mating between the style morphs equal ratios are predicted.

Experiments designed to investigate the function of mirror-image flowers (LK Jesson and SCH Barrett, unpublished data) have been based on the assumption that enantiostylous species are derived from straightstyled ancestors and that dimorphic enantiostyly is derived from monomorphic enantiostyly. Phylogenetic evidence reviewed elsewhere supports these assumptions (Barrett et al, 2000a; LK Jesson and SCH Barrett, unpublished data). Experiments have employed either genetic markers or histochemically stained pollen to compare levels of geitonogamy among the three stylar conditions. The stylar conditions were created by floral manipulations in separate experiments using three enantiostylous species (Solanum rostratum - Solanaceae, and Dilatris corymbosa and $W$. panicululata Haemodoraceae). It was predicted that monomorphic enantiostyly should reduce levels of geitonogamy compared with the non-enantiostylous condition. This is because, in theory, pollen transfer within inflorescences should only occur between alternate flower types in plants with monomorphic enantiostyly because of segregated pollen deposition but could potentially occur between all flowers in straight-styled plants (see Barrett et al, 2000a). The lowest level of geitonogamy was predicted for dimorphic enantiostyly. Collectively the results of these experiments provide some support for the hypothesis that enantiostyly functions to promote crosspollination by reducing levels of geitonogamy. Like heterostyly, these stylar polymorphisms resolve the conflict between precise pollen transfer between plants and the avoidance of self-pollination and interference between sexual functions. The recent discovery of a novel stylar polymorphism termed flexistyly (Li et al, 2001a, b) involving both spatial and temporal segregation of sex roles seems likely to function in a similar manner.

\section{Conclusions}

Through the use of experiments involving floral manipulations it is possible to evaluate forms of sexual interference in plants and their potential ecological and evolutionary significance. While the empirical evidence in support of the sexual interference hypothesis remains limited this should not deter future work on this topic. Many angiosperms possess physiological self-incompatibility and hence are largely outcrossing. Among selfincompatible species, many also exhibit floral traits that have been interpreted as 'back-up systems' preventing selfing or that 'reinforce outcrossing'. Such terms convey little precise meaning and it seems reasonable to consider other adaptive explanations that focus equally on both female and male function. Imaginative experiments are required to disentangle the functional significance of traits that prevent self-fertilization from those that increase mating opportunities by promoting effective pollen dispersal.

\section{Acknowledgements}

I thank Juan Arroyo, Linley Jesson, and Sean Graham for permission to cite unpublished work, Marcel Dorken, Kay Hodgins and Linley Jesson for constructive comments on the manuscript, and the Natural Sciences and Engineering Council of Canada for funding much of the research discussed in this paper.

\section{References}

Baker AM, Thompson JD, Barrett SCH (2000a). Evolution and maintenance of stigma-height dimorphism in Narcissus. I. Floral variation and style-morph ratios. Heredity 84: 502-513.

Baker AM, Thompson JD, Barrett SCH (2000b). Evolution and maintenance of stigma-height dimorphism in Narcissus. II. Fitness comparisons between style morphs. Heredity 84: 514-524.

Barrett SCH, Glover DE (1985). On the Darwinian hypothesis of the adaptive significance of tristyly. Evolution 39: 766-774.

Barrett SCH, Lloyd DG, Arroyo J (1996). Stylar polymorphisms and the evolution of heterostyly in Narcissus (Amaryllidaceae). In: Lloyd DG, Barrett SCH (eds) Floral Biology: Studies of Floral Evolution in Animal-Pollinated Plants, Chapman and Hall: New York. pp 339-376.

Barrett SCH, Cole WW, Arroyo J, Cruzan MB, Lloyd DG (1997). Sexual polymorphisms in Narcissus triandrus (Amaryllidaceae): is this species tristylous? Heredity 78: 135-145.

Barrett SCH, Jesson LK, Baker AM (2000a). The evolution and function of stylar polymorphisms in flowering plants. Ann Bot 85: 253-265.

Barrett SCH, Baker AM, Jesson LK (2000b). Mating strategies in monocotyledons. In: Wilson KL, Morrison D (eds) Systematics and Evolution of Monocots, CSIRO Publishing: Melbourne. pp 258-269.

Bertin RI (1993). Incidence of monoecy and dichogamy in 
relation to self-fertilization in angiosperms. Am J Bot 80: 557-560.

Bertin RI, Newman CM (1993). Dichogamy in angiosperms. Bot Rev 59: 112-152.

Bertin RI, Sullivan M (1988). Pollen interference and cryptic selffertility in Campsis radicans. Am J Bot 75: 1140-1147.

Broyles SB, Wyatt R (1993). The consequences of self-pollination in Ascelpias exaltata, a self-incompatible milkweed. Am J Bot 80: 41-44.

Charlesworth D, Charlesworth B (1987). Inbreeding depression and its evolutionary consequences. Ann Rev Ecol Syst 18 237-268.

Charnov EL, Maynard Smith J, Bull JJ (1976). Why be an hermaphrodite? Nature 263: 125-126.

Darwin C (1876). The Effect of Cross and Self Fertilization in the Vegetable Kingdom. John Murray: London.

Darwin C (1877). The Different Forms of Flowers on Plants of the Same Species. John Murray: London.

Dulberger R (1992). Floral polymorphisms and their functional significance in the heterostylous syndrome. In: Barrett SCH (ed) Evolution and Function of Heterostyly, Springer Verlag: Berlin. pp 41-84.

Fetscher AE (2001). Resolution of male-female conflict in an hermaphrodite flower. Proc R Soc Lond B 268: 525-529.

Galen C, Gregory T, Galloway LF (1989). Costs of selfpollination in a self-incompatible plant, Polemonium viscosum. Am J Bot 76: 1675-1680.

Harder LD, Barrett SCH (1995). Mating cost of large floral displays in hermaphrodite plants. Nature 373: 512-515.

Harder LD, Barrett SCH (1996). Pollen dispersal and mating patterns in animal-pollinated plants. In: Lloyd DG, Barrett SCH (eds) Floral Biology: Studies of Floral Evolution in AnimalPollinated Plants, Chapman and Hall: New York. pp 140-190.

Harder LD, Wilson WG (1998). A clarification of pollen discounting and its joint effect with inbreeding depression on mating-system evolution. Am Nat 152: 684-695.

Harder LD, Barrett SCH, Cole WW (2000). Mating consequences of sexual segregation within inflorescences of flowering plants. Proc R Soc Lond B, 267: 315-320.

Jesson LK, Barrett SCH (in press). Enantiostyly in Wachendorfia (Haemodoraceae): The influence of reproductive systems on the maintenance of the polymorphism. Am J Bot.
Kohn JR, Barrett SCH (1992). Floral manipulations reveal the cause of male fitness variation in experimental populations of Eichhornia paniculata (Pontederiaceae). Funct Ecol 6: 590-595.

Li Q-J, Xu Z-F, Kress WJ, Xia Y-M, Zhang L, Deng X-B et al (2001a). Flexible style that encourages outcrossing. Nature 410: 432.

Li Q-J, Xu Z-F, Xia Y-M, Zhang L, Deng X-B, Gao J-Y (2001b). Study of the flexistyly pollination mechanism in Alpinia plants (Zingiberaceae). Acta Bot Sincia 43: 364-369.

Lloyd DG, Yates JMA (1982). Intrasexual selection and the segregation of pollen and stigmas in hermaphrodite plants, exemplified by Wahlenbergia albomarginata (Campanulaceae). Evolution 36: 903-913.

Lloyd DG, Webb CJ (1986). The avoidance of interference between the presentation of pollen and stigmas in angiosperms. I. Dichogamy. New Zeal J Bot 24: 135-162.

Lloyd DG, Wells MS (1992). Reproductive biology of a primitive angiosperm, Pseudowintera colorata (Winteraceae) and the evolution of pollination systems in the Anthophyta. Plant Syst Evol 181: 77-95.

Sage TL, Strumas F, Cole WW, Barrett SCH (1999). Differential ovule development following self- and cross-pollination: the basis of self-sterility in Narcissus triandrus (Amaryllidaceae). Am J Bot 86: 855-870.

Scribailo RW, Barrett SCH (1994). Effects of prior self-pollination on outcrossed seed set in tristylous Pontederia sagittata (Pontederiaceae). Sex Plant Reprod 7: 273-281.

Seavey SF, Carter SK (1993). Self-sterility in Epilobium obcordatum (Onagraceae). Am J Bot 81: 331-338.

Shore JS, Barrett SCH (1984). The effect of pollination intensity and incompatible pollen on seed set in Turnera ulmifolia (Turneraceae). Can J Bot 62: 1298-1303.

Todd JE (1882). On the flowers of Solanum rostratum and Cassia chamaecrista. Am Nat 16: 281-287.

Waser NM, Price MV (1991). Reproductive costs of self-pollination in Ipomopsis aggregata (Polemoniaceae). Am J Bot 78: 1036-1043.

Webb CJ, Lloyd DG (1986). The avoidance of interference between the presentation of pollen and stigmas in angiosperms. II. Herkogamy. New Zeal J Bot 24: 163-178.

Yeo P (1974). Some aspects of heterostyly. New Phytol 75: 147153. 